\title{
A Ordem Mundial no início do Século XXI na Perspectiva da Teoria Crítica
}

\section{Neogramsciana.}

The World Order in the Beginning of the Twenty-first Century in the Perspective of the Neogramscian Critical Theory.

Leandro Wolpert dos Santos ${ }^{1}$

\begin{abstract}
RESUMO
O objetivo deste artigo consiste em avaliar, a partir dos conceitos de hegemonia e estrutura histórica desenvolvidos pela Teoria Crítica Neogramsciana, as mudanças que assinalaram a economia política da ordem mundial na primeira década do século XXI. Argumenta-se que a natureza dessas mudanças foi incremental e não sistêmica, isto é, não representou modificações profundas na ordem hegemônica vigente, capazes de promover a emergência de uma nova estrutura histórica mundial.
\end{abstract}

Palavras-chave: Ordem Mundial; Mudança; Estrutura Histórica.

\begin{abstract}
The purpose of this article is to assess, from the hegemony and historical structure concepts developed by Neogramscian Critical Theory, the changes that marked the political economy of world order in the first decade of this century. It is argued that the nature of these changes was incremental and not systemic, that is, it didn't represent profound changes in the current hegemonic order in order to promote the emergence of a new world historic structure.
\end{abstract}

Keywords: World Order; Change; Historic Structure.

\section{1-INTRODUÇÃo.}

O fim da Guerra Fria, cujo corolário simbólico foi a queda do muro de Berlim em 1989, propagou em nível global tendências na economia política internacional que já vinham sendo gestadas nas décadas de 70 e 80 . 0 desmanche da bipolaridade internacional, ancorada na competição política, econômica e ideológica entre os dois grandes blocos de poder e seus respectivos sistemas socioeconômicos, trouxe consigo, agora no âmbito de uma estrutura de poder unipolar (WOLHFORTH, 1999), o revigoramento e a expansão mundial da hegemonia estadunidense. A ordem mundial que se afigurou nos anos 90 esteve plasmada na vitória do ideário liberal, tanto sob o ponto de vista político, com a disseminação e primazia dos valores da democracia

\footnotetext{
${ }^{1}$ Mestre em Relações Internacionais pela Universidade Federal de Santa Catarina (UFSC). Pesquisador do Grupo de Análise de Política Externa (GAPE). Florianópolis, Brasil.
} 
representativa, quanto econômico, com a universalização do modo de produção e de organização social capitalista através do processo de globalização econômica.

$\mathrm{Na}$ esfera política internacional, com o desmantelamento da antiga União Soviética e a decorrente extinção do Pacto de Varsóvia em 1991, o predomínio militar e a autoridade política dos EUA e seus aliados do ocidente, sob o pretexto de princípios democráticos, de segurança coletiva e de direitos humanos, expandiram-se rumo à África, Ásia Central, Oriente Médio e Europa Oriental. A condução estadunidense da Guerra do Golfo em 1990-91, sob autorização do Conselho de Segurança das Nações Unidas (CSNU), e da Guerra do Kosovo em 1999, sem aprovação do CSNU, mas sob o auspício de uma OTAN (Organização do Tratado do Atlântico Norte) com mandato reformulado e ampliado, corresponderam a momentos emblemáticos da projeção do poder dos Estados Unidos em nível mundial.

No âmbito da economia internacional, sob o respaldo do poder econômico dos EUA e forte orientação das instituições financeiras internacionais capitaneadas pelo FMI (Fundo Monetário Internacional) e pelo Banco Mundial, a economia de mercado autoregulável propagou-se pelo mundo, suplantando formas alternativas de organização econômica e social com maior participação do Estado que, nos últimos anos da Guerra Fria, haviam perdido legitimidade no imaginário social e político, a exemplo das economias planificadas no leste europeu e das economias nacional-desenvolvimentistas de contornos keynesianistas nos países do terceiro mundo. A ampliação do mercado aberto em escala global, por sua vez, significou o aumento do poder estrutural do capital transnacional, sobretudo do capital financeiro, em detrimento não só da autonomia da classe dirigente nacional na gestão de políticas macroeconômicas e de desenvolvimento, mas também da atuação política de outras forças sociais como o capital nacional e o trabalho organizado (GILL; LAW, 2007).

O aspecto estrutural do capital transnacional no pós-Guerra Fria esteve associado a uma dimensão material e normativa. No plano material, coincidiu com a ascensão, agora em escala planetária, das forças sociais e classes dominantes a ele vinculadas, constituindo uma intricada rede transnacional de poder composta por: instituições bancárias, conglomerados de empresas transnacionais produtivas, grupos de investidores e corretores, fundos de pensões, empresas transnacionais de mídias 
envolvidas no setor das finanças (e.g. The Financial Times, The Economist), tecnocratas do mercado, think thanks, governos nacionais, instituições financeiras internacionais (e.g. FMI e Banco Mundial) bem assim organizações intergovernamentais formais (OMC - Organização Mundial do Comércio) e informais (G7² e OCDE - Organização para a Cooperação e Desenvolvimento Econômico). No plano normativo, implicou a universalização, por intermédio das instituições internacionais, de imagens coletivas e padrões procedimentais embebidos no discurso ideológico do neoliberalismo, o qual, ancorado no arcabouço teórico da corrente neoclássica e na nova economia institucional, preconiza

\begin{abstract}
that human well-being can best be advanced by liberating individual entrepreneurial freedoms and skills within an institutional framework characterized by strong private property rights, free markets, and free trade. The role of the state is to create and preserve an institutional framework appropriate to such practices. The state has to guarantee, for example, the quality and integrity of money. It must also set up those military, defense, police, and legal structures and functions required to secure private property rights and to guarantee, by force if need be, the proper functioning of markets. Furthermore, if markets do not exist (in areas such as land, water, education, health care, social security, or environmental pollution) then they must be created, by state action if necessary (HARVEY, 2005, p. 2).
\end{abstract}

Contudo, não demorou muito para que essa configuração da ordem mundial passasse a ser desafiada, sobretudo diante de alguns eventos internacionais que caracterizaram a primeira década do século XXI, entre os quais devem ser destacados: a guerra do Afeganistão em 2001, a segunda guerra do Golfo em 2003 e a crise econômica mundial de 2007-08.

Nesse sentido, o objetivo deste artigo consiste justamente em avaliar, a partir da Teoria Crítica Neogramsciana (TCN), que tipo de mudanças tais eventos ocasionaram na economia política da ordem mundial no início do século XXI. Para tanto, além dessa introdução e das considerações finais, duas outras seções foram elaboradas. $\mathrm{Na}$ primeira, apresenta-se o instrumental teórico que servirá de insumo para a análise do objeto de pesquisa, análise essa que será realizada na segunda seção do trabalho a partir de três dimensões analíticas da ordem internacional, a saber: capacidades materiais, instituições e ideias.

\footnotetext{
${ }^{2}$ Grupo informal composto pelas sete nações de maior desenvolvimento econômico no mundo, sendo elas: EUA, Canadá, Japão, Alemanha, Inglaterra, França e Itália.
} 


\section{2- MUDANÇAS SISTÊMICAS E ESTRUTURAS HISTÓRICAS NA TEORIA CRÍTICA NEOGRAMSCIANA (TCN).}

De acordo com Cox (1981), a preocupação com as mudanças está no cerne dos estudos da Teoria Crítica Neogramsciana. De fato, para o autor, diferentemente das teorias do tipo problem-solving, que tomam como dadas exogenamente as instituições e as relações de poder, a Teoria Crítica tem por objetivo questionar as origens da ordem social vigente, os interesses a que serve, suas perspectivas de mudança e o papel da agência na transformação da realidade social. Assim, a TCN traz consigo um fim eminentemente reflexivo e normativo, qual seja: pensar formas factíveis e viáveis de ordens sociais alternativas que não apenas permitam a libertação do ser humano como também promovam seu potencial (HOFFMAN, 1987). Dessa sorte, como ferramenta metodológica, as teorias críticas esposam a dialética histórica de Marx, que consiste justamente em perlustrar as contradições inerentes às estruturas sociais vigentes que ensejem a possibilidade de mudança (COX, 1981)

Na Teoria Crítica Neogramsciana, o estudo dos processos históricos é crucial para o discernimento de possibilidades de transformação social. Todavia, não é possível compreender a história e a economia política como uma sequência ou série de acontecimentos ou momentos distintos que, quando reunidos, equivalem a um processo de mudança com certos padrões de regularidade. Destarte, a TCN, assim como qualquer abordagem materialista histórica, busca compreender e explicar determinado sistema da ordem mundial considerando-o como um todo historicamente estruturado (GILL, 2007).

De igual modo, a Teoria Crítica, como teoria da história, rejeita explicações por meio de abstrações (a)trans-históricas, como aquelas associadas à ascensão e queda inexorável das hegemonias internacionais de acordo com a evolução dos ciclos globais de acumulação do capital. Por isso, a TCN deve ajustar continuamente suas categorias e ferramentas de análise em consonância ao dinamismo de seu objeto de estudo. Generalizações são possíveis, porém devem estar social e historicamente contextualizadas. Fatores estruturais devem ser investigados, porém somente com a finalidade de identificar os constrangimentos que dificultam a transformação social, sem a preocupação de estabelecer leis universais (HOFFMAN, 1987). 
Nesse sentido, a estrutura social que constrange a agência na ordem internacional não pode ser interpretada como uma estrutura inalterável e inescapável aos atores (como fazem os realistas e os institucionalistas neoliberais quando se debruçam sobre os efeitos da anarquia internacional sobre a interação das unidades); mas sim, como uma estrutura histórica, cuja existência pode ser substancializada de acordo com a configuração particular de Estados e forças sociais em uma determinada época e em condições de existência transitórias (GILL, 2007).

Segundo Cox (1981), as estruturas históricas não determinam a ação dos atores de maneira mecânica, mas constituem o contexto de hábitos, pressões, expectativas e limites dentro dos quais a ação tem lugar. Sendo passíveis de mudança ao longo do tempo, sobretudo através da ação humana, as estruturas históricas são compostas de três elementos (categorias de força) que não guardam precedência ontológica entre si, mas se influenciam mutuamente: as capacidades materiais, as ideias e as instituições.

As capacidades materiais, de potencial construtivo e/ou destrutivo, correspondem, em sua forma dinâmica, a competências organizacionais e tecnológicas, e, em sua forma agregada, aos recursos físicos que a tecnologia pode transformar (e. g. em estoques de equipamentos, como indústrias e armamentos). As ideias podem ser entendidas de duas formas: i) como um conjunto relativamente estável de noções e entendimentos intersubjetivos sobre a natureza das relações sociais e que tendem a perpetuar no tempo hábitos e expectativas de comportamento. São exemplos desse tipo de ideias na política mundial: a noção de que pessoas são organizadas e comandadas por Estados que desposam de autoridade sobre um território delimitado (soberania), de que os Estados se relacionam por meio de agentes diplomáticos e de que é do interesse desses Estados a existência de regras de imunidade diplomática, etc.; ou ii) como imagens coletivas sobre a ordem social, sustentadas por distintos grupos de sujeitos que apresentam diferentes visões sobre a natureza e legitimidade das relações de poder preexistentes, sobre os significados de justiça e do bem público, etc. (COX, 1981). Por fim, de acordo com Cox (1981), as instituições consistem em amálgamas particulares de ideias e capacidades materiais que estão associados à perpetuação de uma determinada ordem social. Nesse sentido, elas

refletem relações de poder prevalecentes no momento em que são criadas e tendem, ao menos inicialmente, encorajar imagens coletivas consistentes a 
essas relações de poder. Eventualmente, instituições assumem vida própria; elas podem se transformar em um campo de batalha entre tendências opostas, ou instituições rivais podem refletir diferentes tendências (COX, 1981, p. 219).

As instituições, nesse sentido, podem ser reflexo de relações de poder, mas podem também implicar a distribuição desigual de recursos materiais entre os países e, assim, criar assimetrias de poder. Outrossim, as instituições produzem imagens coletivas da ordem social, também chamadas de ideologia, mas igualmente são fruto da forma como a realidade social é intersubjetivamente concebida.

Conforme Cox (1981), as estruturas históricas são permeadas por três níveis ou esferas de atividade inter-relacionadas de maneira não necessariamente linear, podendo variar o ponto de partida para a explicação do processo histórico. São elas: i) forças sociais engendradas pelo processo de produção econômica; ii) formas de Estado derivadas dos complexos Estado-sociedade civil ${ }^{3}$; e iii) ordens mundiais correspondentes a configurações particulares de forças que definem sucessivamente a problemática da guerra e da paz. Em cada uma dessas três esferas de atividades, as três categorias de força se combinam para constituição de uma determinada estrutura histórica. Assim,

considered separately, social forces, forms of state, and world orders can be represented in a preliminary approximation as particular configurations of material capabilities, ideas and institutions. Considered in relations to each other, and thus moving toward a fuller representation of historical process, each will be seen as containing, as well bearing the impact of the others (COX, 1981, p. 221).

Nessa representação teórica, uma estrutura histórica coesa e estável é formada quando há coerência entre suas três categorias de força e entre seus três níveis de atividade descritos acima. Nesse caso, observa-se a existência de uma ordem hegemônica. Se assim for, a possibilidade de transformação social na estrutura histórica reside nos momentos de desintegração das hegemonias sociais, ou seja, quando há uma contradição entre as dimensões de capacidades materiais, ideias e instituições, ou um descompasso entre as forças sociais de produção, as formas de Estado e a ordem mundial que sustentam uma determinada ordem hegemônica.

\footnotetext{
${ }^{3}$ A concepção de Estado em Cox (1983), baseada na perspectiva gramsciana, difere muito das correntes tradicionais de RI e EPI já que, além do aparato burocrático e coercitivo da máquina estatal, incorpora em seu conceito elementos da sociedade civil em sua composição, como as classes sociais, as forças de produção, as instituições civis e os quadros de referência ideacional (ideologia). Assim, podem existir diferentes formas de Estado: militaristas, imperialistas, socialistas, nacionalistas, etc. (COX, 1981).
} 
Cox (1983) define hegemonia internacional como uma forma particular de dominação exercida por um Estado e sua classe dominante (hegemon) através da liderança consensual sobre os demais Estados e forças sociais da economia política mundial. A superioridade bélica e econômica é condição necessária, mas não suficiente, para o exercício da hegemonia, a qual deve se alicerçar na construção de uma ordem internacional legítima em que os interesses particulares do hegemon sejam percebidos como interesses universais da ordem social. Para o autor,

\begin{abstract}
hegemony at the international level is thus not merely an order among states. It is an order within a world economy with a dominant mode of production, which penetrates into all countries and links into other subordinate modes of production. It is also a complex of international social relationships, which connect the social classes of the different countries. World hegemony is describable as a social structure, an economic structure, and a political structure; and it can not be simply one of these things but must be all three. World hegemony, furthermore, is expressed in universal norms, institutions and mechanisms, which lay down general rules of behavior for states and for those forces of civil society that act across national boundaries - rules which support the dominant mode of production (COX, 1983, pp. 171-172).
\end{abstract}

Portanto, para avaliar que tipos de mudança assinalaram a ordem mundial no início do século XXI, verificar-se-á como se portaram as três dimensões de forças categóricas da estrutura histórica do pós-Guerra Fria (sumariadas na seção introdutória deste artigo) diante da incidência, nos anos 2000, dos eventos internacionais aludidos na introdução, a saber: a guerra do Afeganistão em 2001, a segunda guerra do Golfo em 2003 e a crise econômica mundial de 2007-08.

\title{
3- ESTRUTURA HISTÓRICA DA ORDEM MUNDIAL NO INÍCIO DO SÉCULO XXI.
}

\section{1- Capacidades Materiais: mudanças relativas na distribuição mundial de poder.}

Pelo menos desde meados dos anos 90, os fundamentos da unipolaridade que se afigurou no imediato pós-Guerra Fria já vinham sendo questionados por autores como Huntington (1999), segundo quem, a despeito da permanência dos Estados Unidos como única superpotência remanescente do sistema internacional, a existência de potências regionais como Alemanha, Japão, China, Rússia, Índia e Brasil revestia de contornos multipolares a estrutura mundial de poder contemporânea. Tal estrutura, de acordo com Huntington (1999), teria, portanto, uma natureza híbrida, sendo denominada de UniMultipolaridade.

Entretanto, foi somente no início dos anos 2000 que essas tendências multipolares se consolidaram na ordem mundial, a partir da concorrência de dois 
movimentos paralelos (LAYNE, 2009, 2012). De um lado, o declínio relativo dos EUA frente ao desgaste de seu poder político e econômico com a guerra do Afeganistão, do Iraque e, sobremaneira, com a crise financeira de 2007-08. De outro lado, a ascensão de potências emergentes do "sul global", capitaneadas pelos integrantes do grupo BRICS (Brasil, Rússia, Índia, China e África do Sul), que passaram a ter um peso crescente na economia política mundial, principalmente no contexto de crise internacional, quando então esses países contribuíram sobremaneira para a recuperação da demanda agregada mundial.

De acordo com Patriota (2008), em relação às guerras do Iraque e do Afeganistão, embora Washington tenha conseguido impor sua "mudança de regime" por meios militares, a grande instabilidade político-social nesses países plasmada na resistência de lideranças locais, na dinâmica de guerra de guerrilha, na lógica das disputas entre facções políticas e religiosas, etc., foi subestimada pelo governo dos Estados Unidos e acabou por relativizar o potencial da maior máquina militar da história de gerar resultados. Além disso, a ausência de evidências que comprovassem a presença de armas de destruição em massa no Iraque, motivo que justificou a invasão militar estadunidense em 2003, provocou, na leitura de analistas de diferentes tendências, danos consideráveis à imagem internacional da superpotência. De igual modo, outros aspectos relativos à política dos EUA de combate ao terrorismo, como aqueles ligados à prisão de Guantánamo e a seu sistema jurídico próprio, além dos abusos cometidos por militares estadunidenses em Abu Ghraib, afetaram negativamente o soft power de Washington.

Segundo Layne $(2009,2012)$, o colapso financeiro de 2007-08, por sua vez, só fez agudizar um processo de deterioração que já vinha se desenrolando há algum tempo na economia da superpotência: crescimento de déficits nas contas nacionais e o decorrente aumento da desconfiança em relação ao futuro do dólar. 0 primeiro é resultado da combinação de déficits gêmeos em transações correntes - oriundos de desequilíbrios entre o volume das exportações e importações na balança comercial - e nas contas do governo - oriundos do crescimento dos gastos públicos com estímulos 
fiscais ${ }^{4}$ e monetários para o reaquecimento da economia em contexto de depressão, dos gastos militares com o prolongamento das guerras do Afeganistão e Iraque ${ }^{5}$, e dos gastos públicos com a manutenção de programas de assistência social (e.g. Medicare, Social Security, e Medicaid). A junção de todos esses fatores fez com que os Estados Unidos enfrentem até hoje uma crise da dívida pública e dívida externa cujos montantes são quase equivalentes ao que toda sua economia é capaz de produzir em um ano ${ }^{6}$. Para piorar, a sustentabilidade dessa situação só se faz possível, em boa parte, com o financiamento externo das economias emergentes asiáticas, sobretudo da China, que se tornou o maior credor do tesouro público estadunidense na atualidade ${ }^{7}$ (MATA; IZERROUGENE, 2009; LAYNE, 2012).

Conforme Mata e Izerrougene (2009), Layne (2012) e Milan (2012), esses desequilíbrios estruturais na economia estadunidense podem resultar em graves constrangimentos para a projeção de poder dos EUA. Em termos militares, implicam cortes consecutivos no orçamento de defesa desde os anos $2010^{8}$ e a decisão explícita do governo estadunidense de desbaratar boa parte do contingente e porte material utilizado no Iraque e no Afeganistão. Por exemplo, a maior parte dos componentes dos grupos de porta-aviões utilizados no Iraque não foi reorientada para o Pacífico, mas mantida em baixo regime de prontidão nos Estados Unidos (DUARTE, 2013). Em termos financeiros e monetários, colocam em xeque a credibilidade do dólar enquanto reserva de valor e meio de pagamento internacional. Consoante Sennes (2012), o uso do dólar como reserva internacional, que já chegou a $85 \%$ do total das reservas mundiais, baixou

\footnotetext{
${ }^{4}$ Em 2009, a administração Obama, através do American Recovery and Reinvestment Act, injetou 787 bilhões de dólares na economia, configurando uma das maiores operações de resgate na história mundial (JUNIOR; BERTELLA, 2013).

${ }^{5}$ Conforme Duarte (2013), vem ocorrendo ano a ano desde de 2001 um padrão de aumento do orçamento estadunidense de defesa que até 2009 acumulou um aumento real em torno de $75 \%$, e em termos percentuais do PIB de 3 para quase $5 \%$.
}

${ }^{6}$ Em 2013, a relação dívida pública bruta/PIB nos Estados Unidos foi de 96,1\% (BANCO MUNDIAL, 2016). 0 montante da dívida externa estadunidense foi de US\$15,68 trilhões em 2012 (CIA, 2016).

\footnotetext{
${ }^{7}$ Segundo Milan (2012, p. 140), em 2012, a maior parte dos títulos da dívida estadunidense encontrava-se "nas mãos de governos asiáticos, principalmente fundos de riqueza soberana: China com US\$2,5 trilhões, Japão com US\$ 1 trilhão e Taiwan, Hong Kong, Cingapura e Coréia do Sul com US\$ 700 bilhões".

${ }^{8}$ Em 2011, o governo Obama fez a proposta de cortar US\$ 400 milhões em gastos militares onze anos (LAYNE, 2012). De 2010 a 2012, os cortes já totalizaram US\$50,2 milhões de dólares (MORAES; FILHO, 2013).
} 
para de menos de 60\% em 2012. Já segundo Mata e Izerrougene (2009), é cada vez mais comum nas transições comerciais de países como China, Rússia, Venezuela e Irã o escambo ou o uso de moedas nacionais e alternativas em substituição ao dólar9.

De outro lado, observa-se a ascensão de potências emergentes, em especial os integrantes dos BRICS. Segundo Manzi (2014, p. 4), “os BRICS elevaram sua participação na economia mundial de $11,2 \%$ em 1990 , para $16,9 \%$ em 2000 , e $25,2 \%$ em 2010 . Ao mesmo tempo, o G7 reduziu sua participação no PIB mundial de 55,8\% em 1990, para 49,1\% em 2000, e 39,5\% em 2010". Em termos individuais, em 2002, a Rússia figurava como a 19aㅗ maior economia do mundo, o Brasil, como a $13^{a}$, a Índia, como a $12^{\underline{a}}$ e a China, como a 6 $6^{\underline{a}}$ maior economia. Em 2010, a Rússia despontava como a 11aㅡ maior economia do mundo, o Brasil, como a 7aa a Índia, como a 9a e a China, como a $2^{a}$ maior economia (BANCO MUNDIAL, 2016).

Todavia, foi a ascensão da China que mais realçou o declínio relativo do poder estadunidense, a ponto de ter havido, para Layne (2012), uma clara transferência do poder econômico do atlântico norte rumo ao continente asiático. Conforme as estatísticas de Guimarães (2012), desde 1978, com a implementação das reformas liberalizantes por Deng Xiaoping, a China vem crescendo a taxas muito elevadas, próximas à média de $9 \%$ ao ano. Isso permitiu que a economia chinesa assumisse uma importância cada vez significativa no mundo: sua participação no PIB global passou de 2\% em 1980 para 6\% em 1995 para saltar aproximadamente a 13\% em 2014. Quando se compara em termos de paridade de poder de compra, o PIB da China já é superior ao dos Estados Unidos (CIA, 2016). A China também desbancou os EUA na produção maquinofatureira, tornando-se a fábrica do mundo em 2010 (GUIMARÃES, 2012; LAYNE, 2012).

De acordo com Guimarães (2012), a China vem cada vez mais projetando sua influência externa na economia internacional, por meio da assinatura de acordos de livre comércio; do fomento do investimento externo, sobretudo na África, mas também na América Latina e no sudeste asiático, em busca de recursos naturais estratégicos e

\footnotetext{
${ }^{9}$ Em 2010, por exemplo, os governos nacionais de Rússia e China autorizaram suas empresas a evitar o dólar no comércio exterior bem como estimularam o uso de suas moedas locais (o rublo russo e o yuan chinês) em suas transações bilaterais com o fito de diminuir a importância do dólar estadunidense (PANT, 2013).
} 
acesso privilegiado a mercados consumidores; da aquisição de empresas multinacionais nos países desenvolvidos para promover a transferência tecnológica; e, por fim, através de políticas de cooperação técnica com países subdesenvolvidos. De todas as formas, ao estabelecer parcerias com a periferia do sistema e com as nações emergentes, a China procura tomar iniciativas e realizar negócios em que sua moeda nacional possa ser utilizada em substituição ao dólar (MATA; IZERROUGENE, 2009; MILAN, 2012). Em 2012, por exemplo, durante a Quarta Cúpula do BRICS, o governo chinês foi um dos maiores incentivadores para a assinatura do acordo Master Agreement on Extending Credit Facility in Local Currencies, que estabelece mecanismos para que os cinco bancos oficiais dos países integrantes negociem empréstimos em moeda local e possam estimular investimentos e o intercâmbio comercial intra-grupo (VISENTINI, 2013).

Também na esfera militar, a ascensão chinesa é notória, ainda que não tanto quanto nos assuntos econômicos. De fato, além de já possuir o segundo maior orçamento militar do mundo e a maior marinha de guerra da Ásia Oriental, o governo chinês está promovendo uma rápida modernização de suas forças armadas que lhe capacita resguardar sua soberania diante de uma possível intervenção estadunidense (DUARTE, 2013). Para Montgomery (2014), mais que isso, a China já é capaz de conformar com os EUA uma balança de poder no Pacífico, embora em pé de desigualdade.

A despeito de todos os argumentos levantados acima, não se deve sobreestimar a ascensão das potências emergentes (inclusive a própria China) que, além de agora começarem a sentir os efeitos da crise econômica internacional sob a forma de desaceleração - quando não reversão, do crescimento do PIB, suas sociedades nacionais são historicamente cravadas por sérios problemas relacionados à desigualdade social, pobreza, fome, corrupção, carência por serviços públicos, etc. (PANT, 2013). Por outro lado, também não se deve subestimar as capacidades materiais de que ainda gozam os Estados Unidos. Uma breve passagem pelo minucioso levantamento de dados feito por autores como Ikenberry et. al. (2009), Beckley (2012) e Duarte (2012) já é suficiente para se convencer sobre a preeminência militar, geopolítica, econômica e tecnológica dos EUA: i) maior orçamento militar do mundo, cujo investimento representa cerca da metade dos gastos militares globais (os gastos militares chineses representam apenas 7,4\% dos mundiais), elevada capacidade de projeção da força por intermédio de uma 
ampla gama de bases militares instaladas em diversas partes do planeta ii) terceiro maior território e terceira maior população do planeta, com localização geopolítica favorável à não formação de equilíbrios regionais de poder (o que não é verdade, por exemplo, no caso chinês, cujo entorno regional é marcado por disputas geopolíticas) e isolamento defensivo que lhes conferem os oceanos Atlântico e Pacífico em relação a possíveis ameaças provenientes de outros continentes; iii) participação econômica de quase $1 / 4$ da PIB mundial; moeda nacional líder na economia internacional com volume próximo a $80 \%$ no comércio mundial (o yuan chinês está em segundo colocado, mas participa apenas com 9,43\% do total de crédito do comércio) e de alta resiliência diante de desequilíbrios externos, haja vista a hodierna valorização do dólar em relação às demais moedas no mundo (RAMPIERI, 2015).

\section{1- Instituições Internacionais: reformas nos regimes de governança global.}

As mudanças na distribuição mundial de capacidades materiais no início do século XXI foram intensas o suficiente para pressionar os alicerces das principais instituições internacionais da estrutura histórica vigente, muito embora não as tenham derrubado. Certamente a crise econômica de 2007-08 correspondeu a um momento emblemático nesse sentido, por duas razões: $1^{\text {o }}$ diferentemente da tendência histórica verificada desde a depressão de 1929, a crise se originou no centro da economia capitalista e não na periferia do sistema; $2^{\circ}$ com o desdobramento da crise, houve a inversão de posições entre países credores e devedores, ou seja, países que tradicionalmente eram tomadores de empréstimo se converteram em doadores e emprestadores. Esse quadro de fatores abalou a percepção de correlação de força e a decorrente interação entre os autores na medida em que os países centrais, capitaneados pelos EUA, se viram obrigados a negociar com as nações emergentes formas multilaterais de contornar a crise. Tudo isso resultou na revigoração do G2010 financeiro e na consequente marginalização do seleto G7 (MANZI, 2014).

Articulados no âmbito do G20, os países emergentes, sobretudo os integrantes do BRICS, passaram a demandar reformas na estrutura de governança e na tomada de

\footnotetext{
10 Fazem parte do G20 financeiro: África do Sul, Alemanha, Arábia Saudita, Argentina, Austrália, Brasil, Canadá, China, Coreia do Sul, Estados Unidos, França, Índia, Indonésia, Itália, Japão, México, Reino Unido, Rússia, Turquia e União Europeia.
} 
decisão das instituições de Bretton Woods, de sorte a refletir melhor o peso crescente das economias emergentes e dos países em desenvolvimento na economia política mundial. Assim, em 2010, na ocasião da Cúpula de Seul, iniciou-se a XIV Revisão de Cotas do FMI, cuja conclusão deveria encerrar-se em 2014, quando então se iniciaria a XV Revisão de Quotas. Pela reforma proposta na XIV Revisão, haverá uma transferência de aproximadamente 6\% das quotas das nações desenvolvidas para as economias emergentes. Com este resultado, a diferença proporcional das quotas entre países centrais e em desenvolvimento, que era de 21\% (60,5\% para economias avançadas e $39,5 \%$ para economias emergentes e em desenvolvimento), foi para aproximadamente $11 \%$ (55,3\% e 44,70\%, respectivamente). Ademais, os BRICs passaram a estar entre os 10 maiores quotistas mundiais (e, por tanto, votantes) do FMI; a China ocupou o $3^{\circ}$ lugar da Alemanha; Inglaterra e França foram rebaixadas uma posição; Estados Unidos e Japão aumentaram sua participação; e a Ásia foi a região que mais se beneficiou. Observa-se, portanto, um realinhamento que mostra o favorecimento da China em detrimento da Europa, bem como a emergência de países semiperiféricos, ao lado, porém, da manutenção da primazia dos EUA, expressa na continuidade de seu poder de veto dentro da instituição (COELHO, 2012). Entretanto, muito embora constitua avanço importante, a reforma ainda não assegura uma representação proporcional ao peso das potências na economia internacional, razão pela qual, sob forte oposição dos países europeus, está prevista nova discussão futura sobre uma nova reforma (COZENDEY, 2012; COELHO; CAPINZAIKI, 2014).

No que toca a estrutura de governança do FMI, a reforma dar-se-á em quatro aspectos principais: i) a composição do Board of Executive Directors será de 24 membros, porém este número sofrerá revisões a cada oito anos; ii) diminuição de duas cadeiras de países europeus avançados em favor dos países emergentes, até a primeira eleição do Board of Executive Directors, quando forem encerradas as reformas da 14ํㅡㄴ emenda; implementação de eleições para a seleção dos membros do Board of Executive Directors, sem possibilidade de indicações; e iii) aumento do escopo do Alternate Executive Director, que é eleito pelo conjunto de países com menor representação em termos de cota, implicando diminuição do número de países necessários para compor o pool (de 19 para 7) (COELHO, 2012). 
Em relação ao Banco Mundial, a resistência dos países centrais à mudança foi menor. Os principais pontos de reforma dizem respeito aos seguintes tópicos: i) aumento do poder de participação e voto dos membros; ii) promoção da accountability e da boa governança; iii) modernização dos serviços financeiros; iv) melhoria da transparência e acesso à informação; e v) revisão da governança interna. Quanto ao primeiro item, há previsão de transferência de $47 \%$ dos direitos de voto aos países em desenvolvimento, sendo o intuito da instituição fazer com que, assim, esses países cheguem a $50 \%$ do total de votos. Todavia, assim como no FMI, essa reforma deixa intacta a posição privilegiada dos Estados Unidos que desfrutam do poder de veto (COELHO, 2012).

Outro importante evento que incidiu no arcabouço institucional da estrutura histórica vigente foi a criação pelos BRICS, em 2014, do Arranjo Contingente de Reservas (ACR) e do Novo Banco de Desenvolvimento (NBD), como instrumentos de pressão para a conclusão das reformas no FMI. O ACR tem como principal objetivo gerar liquidez por meio de swaps de divisas em resposta a pressões de curto prazo reais ou potenciais sobre o balanço de pagamentos dos países membros. Em outras palavras, este fundo consiste em um compromisso entre os BRICS de disponibilizarem, caso requerido, parte de suas reservas na proteção de seus integrantes contra eventuais turbulências internacionais e ataques especulativos. O NBD, por sua vez, usando como justificativa a forte restrição de crédito internacional e da incapacidade das instituições multilaterais hoje existentes em atender a grande demanda por investimento por parte dos países em desenvolvimento, tem como propósito mobilizar recursos para projetos de infraestrutura e desenvolvimento sustentável nos BRICS e em outras economias emergentes e em desenvolvimento (NDB, 2014).

Além de consistir em um meio de pressionar, sobretudo depois do incumprimento da $14^{\circ}$ revisão de cotas no FMI, as organizações multilaterais de crédito hoje existentes, o ACR e o NBD contribuem para institucionalizar o BRICS, amenizar a vulnerabilidade de seus integrantes frente os países centrais e incrementar o poder de influência do grupo na governança financeira global. Em acréscimo, essa iniciativa concorre em parte para a democratização mundial da oferta de crédito ao facultar mais opções e mais recursos aos países tomadores de empréstimos, favorecidos pela concorrência (MOREIRA JR, 2014). 
Contudo, é de se notar o papel eminentemente reformista e não revolucionário do ACR e do NBD no sistema financeira internacional. Primeiro, porque os líderes dos BRICS declaradamente assumem que esses mecanismos de crédito vêm para complementar e não substituir as instituições multilaterais de Bretton Woods. E segundo porque, tanto o fundo como o banco do BRICS empregam procedimentos, quando não idênticos, parecidos aos daquelas instituições. Por exemplo, enquanto a tomada de decisão no NBD é baseada em quotas de participação de seus países membros, à semelhança do Banco Mundial, a concessão de 70\% dos recursos do ACR destinados a momentos de crise é disciplinada pelas condicionalidades do FMI (ACR, 2014; MOREIRA JR, 2014).

Por fim, no que tange ao tema da segurança internacional, uma tentativa de reforma também foi buscada, embora com muito menos sucesso em comparação às instituições financeiras. Aqui, novamente, alguns dos principais atores envolvidos são integrantes do grupo BRICS, que, pelo menos no plano discursivo, preconizam a necessidade de se reformar o Conselho de Segurança das Nações Unidas, com a China e a Rússia, membros permanentes, dando seu apoio à aspiração de Brasil, Índia e África do Sul de desempenhar papel mais protagonista nas Nações Unidas. Entrementes, Silva (2012) nota que, na prática, o ponto que mais importa nessa reforma, qual seja, uma nova constituição do CSNU de modo a torná-lo mais representativo e democrático com a inclusão de novos membros permanentes, provoca divergências provavelmente não conciliáveis entre os próprios países integrantes do BRICS: a China se opõe, entre outros motivos, em função de sua rivalidade geopolítica com a Índia; a Rússia preza pela manutenção do status quo, que lhe permite resguardar sua condição de potência no seleto grupo dos cinco membros permanentes; Brasil e Índia, esta com o apoio declarado dos EUA, são a favor da inclusão do Japão, oponente histórico da China. Desse modo, enquanto Brasil, Índia e África do Sul apresentam intenções reformistas, Rússia e China revelam um perfil conservador.

\section{3- Dimensão Ideacional: neoliberalismo e liderança estadunidense em questionamento.}

De todas as dimensões da estrutura histórica vigente, talvez seja no campo das ideias, em particular das imagens coletivas, onde as mudanças trazidas pelo século XXI 
sejam menos perceptíveis e mais fluidas. Uma delas se deu na percepção de demais Estados do sistema internacional, particularmente China e Rússia, sobre a legitimidade ("benevolência") da hegemonia estadunidense após os desdobramentos das guerras do Afeganistão e Iraque. De acordo com Pape (2005) e Paul (2005), a política externa dos EUA impulsionada pela Doutrina Bush de "guerra ao terror", de caráter altamente unilateral, agressivo e descomedido, teria provocado grande consternação nas lideranças políticas dos demais Estados, que passaram a questionar o papel estabilizador do hegemon na ordem mundial. Sentindo-se indiretamente ameaçados, esses líderes começaram a clamar, cada vez mais, pelo retorno a uma ordem multipolar equilibrada e multilateral. Assim, não demorou muito para que se desenvolvessem estratégias de balanceamento que visavam resguardar, sem confrontação militar direta, a autonomia nacional desses Estados diante da ingerência estadunidense, por meio de forte ativismo político nos fóruns e instituições multilaterais. São resultados dessa estratégia as coalizões feitas sobretudo entre países emergentes e em desenvolvimento, como o BRICS, o IBAS (Índia, Brasil e África do Sul), a OCX (Organização para Cooperação de Xangai), o G-20 comercial, e União Eurasiática, etc.

Entretanto, mais uma vez, o principal evento que impactou a dimensão ideacional da estrutura histórica do pós-Guerra Fria foi a crise econômica de 2007-08, que colocou em questionamento, pelo menos superficialmente e ainda que por um período limitado de tempo, a legitimidade da imagem coletiva dominante e a força social ligada a ela, respectivamente: o neoliberalismo econômico e o capital financeiro transnacional (as altas finanças). ${ }^{11}$ Entrava em processo de formação, naquele momento, uma espécie de consenso entre governos, tecnocratas e intelectuais que identificava a desregulamentação e a especulação financeira como uma das principais causas para a eclosão da crise. Assim, parecia haver um anseio pelo que Helleiner (2010) intitula "novo Bretton Woods", capaz de, através do maior controle sobre os fluxos internacionais de capital, transmitir segurança e previsibilidade aos atores de uma economia mundial em alvoroço.

\footnotetext{
${ }^{11}$ Além do neoliberalismo e das altas finanças, o FMI e o G7 também sofreram crise de legitimidade. Este, como dito alhures, pelo fato de o epicentro da crise ter incidido nas economias dos países avançados que o integram. Aquele, por cometer falhas de supervisão das práticas e políticas dos países centrais e ignorar os potenciais riscos das inovações financeiras vistas como promissores (COELHO, 2007).
} 
Destarte, tanto o FMI como o G20 financeiro passaram a instar, pelo menos discursivamente, por maior regulação das finanças internacionais. Para tanto, almejouse homogeneizar as regras e procedimentos de regulação das instituições financeiras (bancárias e não-bancárias) e dos canais de contágio entre as economias por meio da adoção do Basiléia III, que tinha por finalidade: i) aumentar a resistência do setor bancário na absorção de choques externos; ii) melhorar a gestão de risco e aperfeiçoar a governança das instituições financeiras internacionais; e iii) fornecer maior transparência ao setor bancário e aos mercados de derivativos. Por fim, concentraramse esforços internacionais na adoção de medidas que diminuíssem os riscos dos governos nacionais serem obrigados a realizar operações de salvamento ao setor bancário, diminuíssem os riscos decorrentes da existência do "shadow banking" e aumentassem a cooperação internacional para o combate da lavagem de dinheiro oriunda de atividades criminosas e do terrorismo internacional (MARTIN, 2014).

Para Helleiner (2010), no entanto, conforme o tempo transcorreu e o risco de um colapso de todo sistema bancário internacional diminuiu, a agenda regulatória dos mercados financeiros se desvaneceu. Isso em função do pouco afinco apresentado pelos tecnocratas e líderes políticos tanto de países centrais quanto periféricos na implementação das reformas, mas também, sobretudo, devido à forte oposição imposta pelas forças sociais do capital financeiro transnacional que, após um interregno de relativa desarticulação, reassumiram sua hegemonia de classe esposando o recurso da competitividade.

O G20, de igual modo, também acabou se esvaziando com o tempo. Uma combinação de fatores concorreram para tanto, dos quais se destacam: a perda de foco e de consenso no grupo com a ampliação da agenda de discussão, incluindo-se temas como desequilíbrios macroeconômicos globais, sustentabilidade ambiental, uso do dólar como moeda internacional, etc.; as críticas sobre a legitimidade do G-20, o qual, embora represente $85 \%$ do PIB global, ainda é um grupo muito seleto por não abrigar a maior parte dos países do globo, nenhuma nações africana, nenhum país de baixa renda; ao passo que países da zona do euro possuem duas representações, uma individual e outra no âmbito da EU, que é considerada um membro (HELLEINER, 2010; COELHO; CAPINZAIKI, 2014). Em paralelo ao paulatino esmaecimento do G-20, o multilateralismo 
cedeu terreno para o plurilateralismo, com as ideias neoliberais e as altas finanças retomando o controle da estrutura histórica.

\section{4- CONSIDERAÇÕES FINAIS.}

Baseado na Teoria Crítica Neogramsciana (TCN), este artigo buscou avaliar de que modo a estrutura histórica da ordem mundial que se afigurou no pós-Guerra Fria modificou-se diante da incidência de eventos sistêmicos que assinalaram o contexto internacional no início do século XXI, cite-se: a guerra do Afeganistão em 2001, a segunda guerra do Golfo em 2003 e a crise financeira e econômica mundial de 2007-08. 0 desenvolvimento da pesquisa mostrou que mudanças importantes aconteceram nas três dimensões analíticas: nas capacidades materiais, observaram-se alterações gradativas na distribuição mundial de poder com o declínio relativo dos EUA e a ascensão de países emergentes, sobretudo da China; nas instituições internacionais, o FMI e o Banco Mundial sofreram reformas em sua estrutura de governança e no processo de tomada de decisão, com a transferência de cotas dos países desenvolvidos para os emergentes e subdesenvolvidos. No Conselho de Segurança da ONU, em contraste, as reformas sequer tomaram corpo, em razão de diferenças existentes entre seus proponentes. Por outro lado, novas instituições surgiram e se revigoraram, como o NDB e G20, respectivamente; na dimensão ideacional, a legitimidade de algumas imagens coletivas foi questionada, como a liderança estadunidense e o modelo econômico neoliberal. 0 questionamento da primeira resultou no compartilhamento intersubjetivo por parte de alguns atores do anseio por uma ordem multipolar balanceada. Já o questionamento do segundo teve vida curta e logo se desarticulou com o esvaziamento do G-20.

Apesar de indicarem tendências que, em longo prazo, podem ter desdobramentos profundos, nenhuma das mudanças identificadas acima significou a completa transformação dos fundamentos da estrutura histórica hegemônica. Primeiro, a estrutura de poder mundial se encontra em transição da 'uni' para a multipolaridade, no entanto, a preeminência militar, geopolítica, econômica e geopolítica dos EUA ainda se mantém. Segundo, as principais reformas institucionais até agora logradas não foram suficientes para alterar efetivamente a correlação de forças entre os principais atores do sistema internacional. A redistribuição das cotas no FMI, por exemplo, não invalida a 
posição de veto e de controle de que ainda gozam os Estados Unidos dentro desta instituição. Além disso, essas reformas não atingem os princípios da imagem coletiva, a ideologia, se assim se prefere, que permite o exercício da hegemonia da força social dominante. Com efeito, o NDB e o ACR, antes de serem substitutos, são complementares às instituições vigentes, porquanto não dispõem de um quadro próprio e antagônico de imagens coletivas. A reforma do CSNU, por sua vez, como já foi dito, se quer saiu do papel, e não há previsões de que avanços venham a ocorrer no médio prazo, a despeito do intenso e prolongado debate que o assunto engendrou no começo dos anos 2000.

Terceiro, embora tenha colocado em discussão a legitimidade da economia neoliberal, a crise econômica de 2007-08 e as forças sociais contra-hegemônicas então existentes não conseguiram enquadrar os interesses hegemônicos das altas finanças. Em parte, devido ao poder estrutural do capital financeiro transnacional descrito na seção introdutória. Mas, também, porque não foi organizado um projeto contra-hegemônico que pudesse servir de alternativa ao que então estava dado: os países emergentes não possuem coordenação suficiente para tanto, e a China, que talvez correspondesse à força que mais se aproxima das condições necessárias, ao que tudo indica não está disposta a fazê-lo, já que seus interesses nacionais ainda conseguem se adequar às normas e instituições da estrutura histórica prevalecente.

Portanto, conclui-se que as mudanças verificadas na economia política da estrutura histórica no início do século XXI correspondem a mudanças incrementais e não sistêmicas, isto é, não representaram modificações profundas na ordem hegemônica dos anos 90, capazes de promover a emergência de uma nova estrutura histórica mundial.

\section{REFERÊNCIAS BIBLIOGRÁFICAS.}

BANCO MUNDIAL. Datos. Disponível em: http://datos.bancomundial.org/. Acesso em: 23/09/2016;

CIA. The World Factbook. 2016. Disponível em: https://www.cia.gov /library /publications /the-world-factbook/geos/us.html. Acesso em: 23/09/2016;

COELHO, J. C. Reformando as instituições financeiras multilaterais (passado e presente): Banco Mundial e Fundo Monetário Internacional. In: CINTRA, M. A.M. et al (Orgs.) As 
Transformações no Sistema Financeiro internacional, IPEA, vol. 2, 2012. po. 605645;

COELHO, J. C.; CAPINZAIK, M. R. Desdobramentos da crise financeira de 2007-08: reforma da arquitetura financeira tradicional e inovações no desenho institucional do regime financeiro internacional. In: Carta Internacional, v. 9, n. 1, 2014, pp. 144-160;

COX, R. W. Social Forces, States and World Orders: Beyond International Relations Theory. In: Millennium, v. 10, n. 2, 1981, pp. 126-155;

COX, R. W. Gramsci, Hegemony and International Relations: An Essay in Method. In: Millennium, v. 12, n. 2, 1983, pp. 162-175;

COZENDEY, C. M. BRIC a BRICS num mundo em transição. In: PIMENTEL, José Vicente de Sá (Org). 0 Brasil, os BRICS e a Agenda Internacional. Brasília, FUNAG, 2012, pp. 1071167;

CRA. Treaty for the Establishment of a BRICS Contingent Reserve Arrangement, 2014. Disponível em: http://brics6.itamaraty.gov.br/pt_br/imprensa/comunicados-deimprensa/218-tratado-para-o-estabelecimento-do-arranjo-contingente-de-reservas-dobrics-fortaleza-15-de-julho. Acesso em: 23/09/16;

DUARTE, E. E. Poder Militar, Crise Financeira e o Panorama de Segurança Internacional do Século XXI. In: Austral: Revista Brasileira de Estratégia e Relações Internacionais. Porto Alegre: v.2, n.3, 2013, pp.11-45;

GILL, Stephen. Epistemologia, Ontologia e a "Escola Italiana". In: GILL, Stephen (Org). Gramsci: materialismo histórico e relações internacionais. Rio de Janeiro, Editora UERJ, 2007, pp. 65-99;

GILL, Stephen; LAW, David. Hegemonia Global e o Poder Estrutural do Capital. In: GILL, Stephen (Org). Gramsci: materialismo histórico e relações internacionais. Rio de Janeiro, Editora UERJ, 2007, pp. 157-200;

GUIMARÃES, A. Q. A Economia Política do Modelo Econômico Chinês: o Estado, o Mercado e os Principais Desafios. In: Revista Sociologia Política. Curitiba: v. 20, n. 44, 2012, pp. 103-120;

HELLEINER, Eric. A Bretton Woods moment? The 2007-2008 crisis and the future of global finance. In: International Affairs, v. 86, n. 3, 2010, pp. 619-636/

HOFFMAN, Mark. Critical Theory and the Inter-Paradigm Debate. In: Millennium, v. 16, n. 2, 1987, pp. 231-250;

HUNTINGTON, S. P. The Lonely Superpower. In: Foreign Affais, march/april, 1999;

LAYNE, Christopher. The Unipolar Illusion Revisited: the Coming End of United States' Unipolar Moment. In: International Security, v. 31, n. 2, 2009, pp: 7-41;

This Time It's Real: The End of Unipolarity and the Pax Americana. International Studies Quarterly, 56, 2012, pp. 203-13;

MANZI, R. E. D. A Transição G7 - G20 e os BRICS na Ordem Econômica Internacional. In: Os BRICS e a Transformação da Ordem Global - II Seminário de Relações Internacionais: Graduação e Pós-Graduação. Associação Brasileira de Relações Internacionais (ABRI), João Pessoa, 2014; 
MATA, H. T. da C.; IZERROUGENE, Bouzid. Desequilíbrios Norte-americanos, Novas Práticas Comerciais e Enfraquecimento do Dólar. In: Contexto Internacional. Rio de Janeiro: v. 31, n. 1, 2009, pp. 159-188;

MILAN, Marcelo. A Crise Financeira e a Hegemonia do Dólar. In: Austral: Revista Brasileira de Estratégia e Relações Internacionais. Porto Alegre: v.1, n.1, 2012, pp.133-148;

MONTGOMERY, E. B. Contested Primacy in the Western Pacific: China's Rise and the Future of U.S. Power Projection. In: International Security, v. 38, n. 4, 2014, pp. 115149;

MORAES, R. F. de.; FILHO, E. B. da S. Brics Military Modernization in a Context of Transition in the Patterns of Global Military Expenditures. In: (Org) BRICS Academic Forum. BRICS and Africa: Partnership for Development, Integration and Industrialisation. Department of International Relations and Cooperation (DIRCO), 2014;

MOREIRA JR, Hermes. O Banco dos BRICS e os Cenários de Recomposição da Ordem Internacional. In: Os BRICS e a Transformação da Ordem Global - II Seminário de Relações Internacionais: Graduação e Pós-Graduação. Associação Brasileira de Relações Internacionais (ABRI), João Pessoa, 2014;

NDB. Agreement on the New Development Bank, 2014. Disponível em: http://brics6.itamaraty.gov.br/pt_br/imprensa/comunicados-de-imprensa/217agreement-on-the-new-development-bank-fortaleza-15-de-julho. Acesso em: 23/09/2016;

PANT, Harsh V. The BRICS Fallacy. The Washington Quarterly, 36:3, Summer 2013, pp. 91-105;

PAPE, R. A. Soft balancing against the United States. In: International Security, v. 30, n. 1, 2005, pp. 7-45;

PAUL, T. V. Soft balancing in the age of U.S. primacy In: International Security, v. 30, n. 1, 2005, pp. 46-71;

PATRIOTA, Antonio de Aguiar. O Brasil e a Política Externa dos EUA. In: Política Externa, v. 17, n. 1, 2008;

RAMALHO, A. G. O Brasil, os BRICS e a agenda internacional: ceticismo, intersecções e oportunidades. In: PIMENTEL, José Vicente de Sá (org).O Brasil, os BRICS e a Agenda Internacional. Brasília, FUNAG, 2012, pp. 87-99;

RAMPIERI, R. T. Não é só no Brasil: veja outras moedas em que o dólar está em máximas históricas. Portal InfoMoney, 06-03-2015. Disponível em: http://www infomoney .com.br /mercados/ cambio/noticia/3900241/nao-brasil-veja-outras-moedas-quedolar-esta-maximas-historicas. Acesso em: 23/09/2016;

SENNES, Ricardo. o engajamento internacional minimalista e seletivo dos BRICS. In: PIMENTEL, José Vicente de Sá (org). O Brasil, os BRICS e a Agenda Internacional. Brasília, FUNAG, 2012, pp. 217-234;

SILVA, C. E. L. da. BRICS: De acrônimo esperto a fórum influente. In: PIMENTEL, José Vicente de Sá (org). O Brasil, os BRICS e a Agenda Internacional. Brasília, FUNAG, 2012, pp. 101-106; 
VISENTINI, P. F. Brics, OCX e Ibas: as coalizões dos emergentes. In: VISENTINI, P. F. et. al.BRICS: as potências emergentes. Petrópolis: Editora Vozes, 2013;

WOHLFORTH, W. C. The Stability of a Unipolar World. In: International Security, v.24, n.1, 1999, pp. 5-41;

YKENBERRY, G. J.; MASTANDUNO, Michael; WOHLFORTH, W. C. Unipolarity, State Behavior, and Systemic Consequences. In: World Politics, n. 61, january 2009, pp. 1-27; 